\title{
Two electrical conductors beneath Kusatsu-Shirane volcano, Japan, imaged by audiomagnetotellurics, and their implications for the hydrothermal system
}

\author{
Nurhasan $^{1}$, Yasuo Ogawa ${ }^{2}$, Naoto Ujihara ${ }^{1 *}$, S. Bulent Tank ${ }^{1 \dagger}$, Yoshimori Honkura ${ }^{1}$, Shin’ya Onizawa ${ }^{2,3}$, \\ Takehiko Mori ${ }^{2,3}$, and Masahiko Makino ${ }^{3}$ \\ ${ }^{1}$ Department of Earth and Planetary Sciences, Tokyo Institute of Technology, Tokyo 152-8551, Japan \\ ${ }^{2}$ Volcanic Fluid Research Center, Tokyo Institute of Technology, Tokyo 152-8551, Japan \\ ${ }^{3}$ Geological Survey of Japan, AIST, Tsukuba, Ibaraki 305-8567, Japan
}

(Received November 14, 2005; Revised April 19, 2006; Accepted April 24, 2006; Online published September 16, 2006)

\begin{abstract}
Kusatsu-Shirane volcano, Japan, is known for its active phreatic eruptions. We have investigated its hydrothermal system by conducting audio-magnetotelluric soundings at 22 stations along a profile that extends across the volcano. The final two-dimensional model is characterized by two conductors. One is a 300- to 1000-m-thick conductor of 1-10 $\Omega \mathrm{m}$, which is located on the eastern slope and covered with $200-\mathrm{m}$-thick resistive layers of Kusatsu-Shirane lava and pyroclastics. This conductor indicates the presence of a Montmorillonite-rich layer of Pliocene volcanic rocks that may function both as an impermeable floor for the shallow fluid path from the peak to the hot springs to the east and as an impermeable cap for the deeper fluid path from the summit region to the foot of the volcano. The second conductor is found at a depth of 1-2 km from the surface, at the peak of the volcano, and its resistivity is as low as $1 \Omega \mathrm{m}$ or less. This low resistivity can be explained by fluids containing high concentrations of chloride and sulfate which were supplied from the magmatic gases. Micro-earthquakes cluster above this conductor, and the cut-off of the earthquakes corresponds to the top of the conductor. This conductor infers the presence of the fluid reservoir, and the upward release of these fluids from the reservoir through the conduit presumably triggers the micro-earthquakes at the peak area of the volcano. Crustal deformation modeling using GPS and leveling data of the past 10 years revealed that the center of the deflation coincides with the top of the second conductor, indicating that the fluid reservoir itself can be hosting the deformation.
\end{abstract}

Key words: Resistivity, volcano, magnetotellurics, Montmorillonite, clay, fluid.

\section{Introduction}

Mt. Kusatsu-Shirane is a Quaternary andesitic-to-dacitic active volcano situated in Central Japan at the southern end of the Northeast Japan arc (Fig. 1), where the volcanic front bends towards the south. It is a stratovolcano that is located at the eastern edge of the elevated Tertiary basement, called the Central Uplift Zone (Takeda et al., 2004), with an approximately north-south strike. Its volcanic activities have been recorded since 1805 and are characterized by phreatic eruptions (Uto et al., 1983). These eruptions have created many crater pits around the peak of KusatsuShirane volcano (Fig. 1), such as the Yugama, Karegama, and Mizugama craters. The most recent eruptions were of a phreatic nature and occurred in 1982-1983 at the Yugama and Karegama craters. Since then, there have been no eruptions, but there were active periods of volcanic earthquakes early in the 1990s as well as some peculiar geophysical phenomena associated with this activity (Yamazaki et al., 1992;

*Present address: Hydrographic and Oceanographic Department, Japan Coast Guard, Tokyo, Japan.

${ }^{\dagger}$ Present address: Kandilli Observatory and Earthquake Research Institute, Boğaziçi University, İstanbul, Turkey.

Copyright (C) The Society of Geomagnetism and Earth, Planetary and Space Sciences (SGEPSS); The Seismological Society of Japan; The Volcanological Society of Japan; The Geodetic Society of Japan; The Japanese Society for Planetary Sciences; TERRAPUB
Kumagai et al., 2002; Nakano et al., 2003).

An understanding of the hydrothermal system provides important data within the context of monitoring the phreatic eruption environment. There have been intensive geochemical studies on volcanic fluids and gases with special reference to the largest crater lake, Yugama (see Kikawada et al., 1993; Sano et al., 1994; Hirabayashi, 1999; Ohba et al., 1994, 2000). Ohba et al. (2000) demonstrated the origins and the mixing processes of volcanic fluids and gases along a profile extending across the Kusatsu-Shirane volcano based on isotope data of hydrogen and oxygen. However, the geochemical model remains qualitative in imaging the geothermal system.

The objective of our on-going research project is to spatially constrain the hydrothermal system in terms of resistivity structure using the audio-frequency magnetotelluric (AMT) method. We use natural electromagnetic fields in the frequency range between $10 \mathrm{KHz}$ and $1 \mathrm{~Hz}$. Electromagnetic methods are widely used for the imaging of active volcanoes because the resistivity is sensitive to the fluids and the clay alteration minerals (Ogawa and Takakura, 1990; Ogawa et al., 1992, 1998, 1999; Pellerin et al., 1996; Di Maio et al., 1998; Kagiyama et al., 1999; Fuji-ta et al., 1999; Matsushima et al., 2001; Müller and Haak, 2004; Çağlar and İşseven, 2004; Manzella et al., 2004; Oskooi et al., 2005; Aizawa et al., 2005). It must be noted, however, that the interpretation of the conductors as either fluids or 


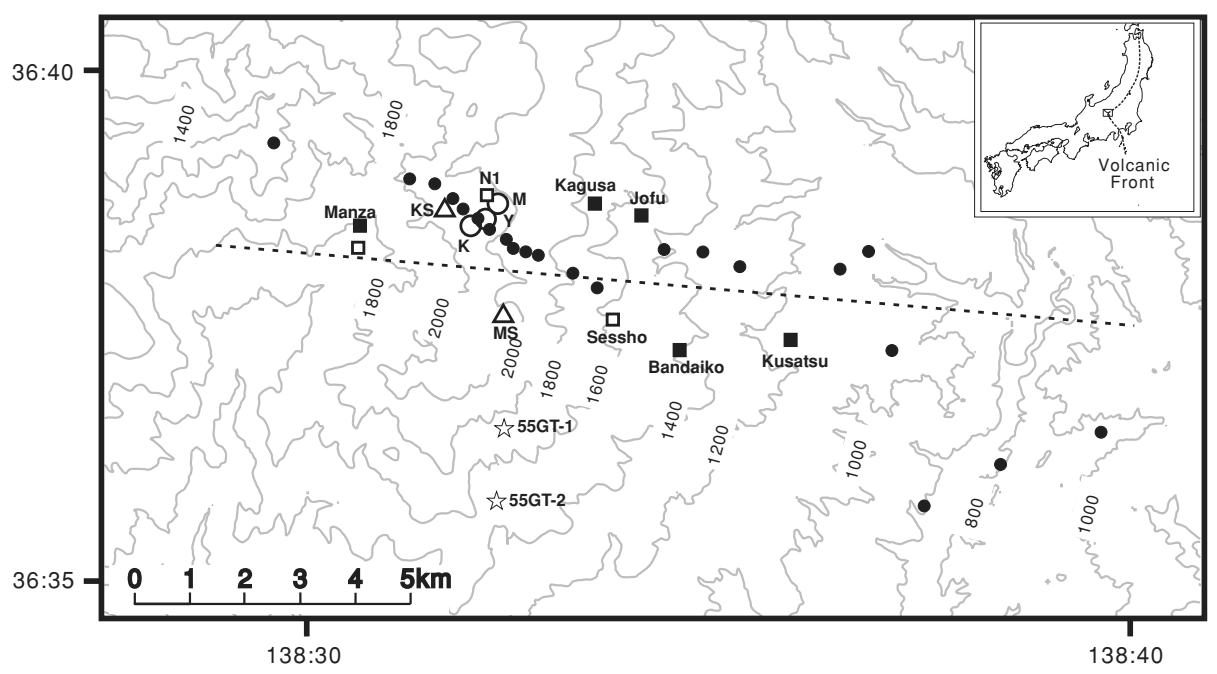

Fig. 1. Small solid circles denote AMT sites. Solid and open squares indicate hot springs and fumaroles. The open triangles (MS and KS) are peaks of Mt. Moto-Shirane and Mt. Kusatsu-Shirane. The circles (K, Y and M) at the peak of the Kusatsu-Shirane volcano are crater pits of the Karegama, Yugama, and Mizugama, respectively. The starts (55GT-1 and 55GT-2) are the 1500-m-class borehole locations. The broken line is the projected profile for the resistivity cross section.

$10000-1000 \mathrm{~Hz}$

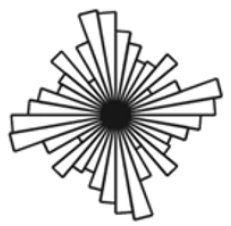

$1000-100 \mathrm{~Hz}$

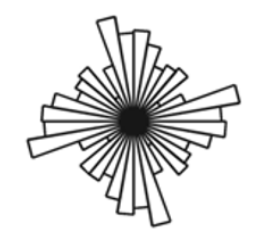

$100-10 \mathrm{~Hz}$
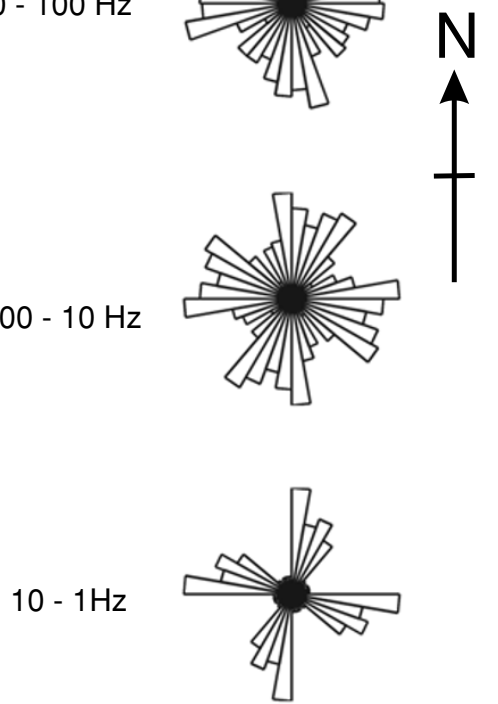

Fig. 2. Rose diagrams of the estimated strikes after Groom-Bailey tensor decompositions for each decade of frequencies. The diagrams are normalized to have the same sizes.

clay minerals can lead to opposing conclusions on the hydrology because fluids require high permeability whereas clay alterations may imply low permeability. In this paper, we interpreted the resistivity model using logging information obtained from 1300- to 1500-m-deep boreholes.

\section{AMT Site Locations and Geological Back- ground}

Figure 1 shows the AMT site locations. There are no exposures of the pre-Tertiary basement in the area, and Miocene formations, mainly composed of marine volcanic rocks, crop out at the western and eastern ends of the profile (Geological Survey of Japan, 1998). Pliocene-Pleistocene lava, which is known as Takai lava, overlies this formation and is exposed at the northwestern slope of the KusatsuShirane volcano (Uto et al., 1983; Kurasawa, 1993; Geological Survey of Japan, 1998). Conversely, the eastern slope of the Kusatsu-Shirane volcano is covered with both Quaternary lava of three different eruption stages and a large amount of Taishi pyroclastic flow deposits (Uto et al., 1983). Based on geothermal test drillings at the southern flank of the volcano (55GT-1 and 55GT-2 in Fig. 1), this Quaternary formation has only a couple of hundred meters thick (Kurasawa, 1993).

There are many geothermal manifestations in the study area (Fig. 1). The active degassing of $\mathrm{H}_{2} \mathrm{~S}$ and $\mathrm{CO}_{2}$ is commonly observed at Manza, N1 (north of Yugama), and at Sessho, although magmatic gas components such as $\mathrm{SO}_{2}$ and $\mathrm{HCl}$ are only rarely observed at these fumaroles, suggesting that the magmatic gases may be absorbed by mixing with underlying abundant fluids (Hirabayashi et al., 1997). Correspondingly, there are many acid hot springs in this area at Manza, Kagusa, Jofu, Bandaiko, and Kusatsu that are characterized by $\mathrm{SO}_{4}^{2-}$ and $\mathrm{Cl}^{-}$. The concentration of these ions decreases from the peak toward the eastern flank (Hirabayashi et al., 1997; Hirabayashi, 1999), indicating that the source of the volcanic fluid is flowing eastward from the peak and that it is mixed with the meteoric water. Helium and carbon isotope distributions also support this model (Sano et al., 1994). However, a recent study on the mass flux of the volatiles $\left(\mathrm{SO}_{4}^{2-}, \mathrm{Cl}^{-}\right)$suggested that this simple fluid flow model cannot explain the large amount of volatile mass flux at the Sessho, Bandaiko, and Kusatsu hot springs (Mizuhashi, 2004). In addition, tritium anal- 

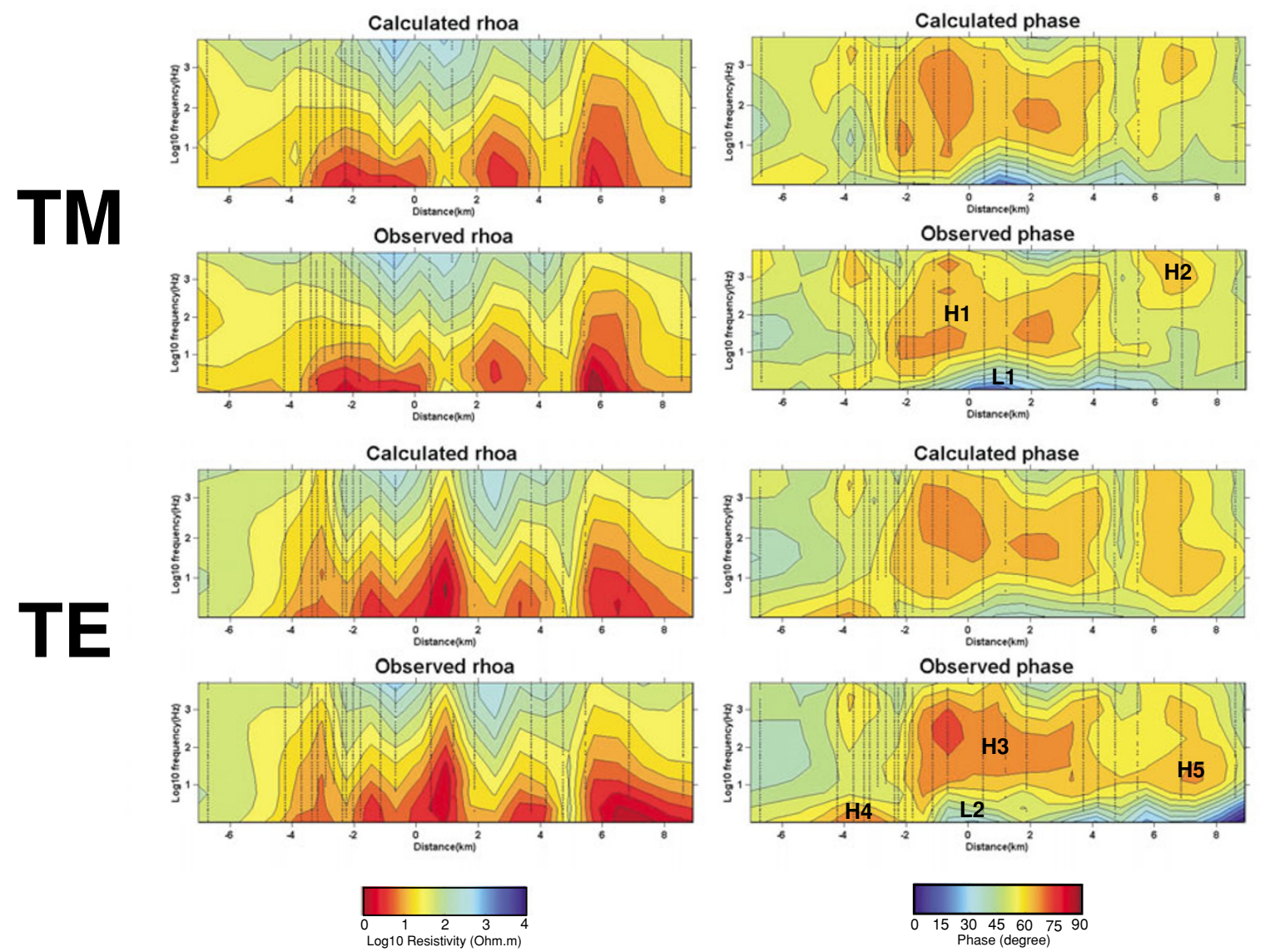

Fig. 3. Calculated and observed pseudo-sections of the apparent resistivity and phase for the TM (above) and TE (below) modes. Major anomalies for the phases are labeled.

yses have shown that the contributing meteoric water will take tens of years to reach the foothills (Hirabayashi et al., 1997). Thus, it is necessary to conduct geophysical imaging of the geothermal system at depth in order to further our understanding of this system.

\section{AMT Measurements}

We have carried out AMT measurements on KusatsuShirane volcano (Fig. 1) by establishing 22 sounding sites aligned along the WNW-ESE direction across the topographic features of the volcano. At the peak of the volcano, the sites were as close as $200 \mathrm{~m}$. We used two sets of Phoenix Geophysics MTU5A systems to measure four components of electromagnetic fields (two horizontal electric fields and two horizontal magnetic fields) in the frequency range between $10 \mathrm{KHz}$ and $1 \mathrm{~Hz}$. The typical electric dipole length was $30 \mathrm{~m}$. Each AMT measurement took 1-2 h. The remote reference technique was also applied to reduce noise contamination.

\section{Dimensionality of the Data}

Although the AMT stations were aligned in a profile (see Ogawa, 2002), it was important to check the dimensionality prior to the analyses. First, the tensor decomposition (Groom and Bailey, 1989) was applied to each frequency and site independently, and strike direction was inferred. Then, the total histogram was summarized for each decade of frequencies as rose diagrams (Fig. 2) in which $\pi / 2$ am- biguity was also taken into account. Throughout the four decades, the strike generally followed the N-S direction, and there was period-dependency of the predominant strike directions. The strikes showed $\mathrm{N} 10^{\circ} \mathrm{W}$ to $\mathrm{N} 20^{\circ} \mathrm{W}$ in the higher two decades and $\mathrm{N} 0^{\circ} \mathrm{E}$ to $\mathrm{N} 10^{\circ} \mathrm{E}$ in the lower frequencies. In the subsequent analyses, we focused on the deep structure of the region and chose $\mathrm{N} 5^{\circ} \mathrm{E}$ as a regional strike. With the ambiguity of $\pi / 2$, there was the other possibility of choosing the strike as $\mathrm{N} 95^{\circ} \mathrm{E}$, but this was rejected based on the general known geological strike as $\mathrm{N}$ $\mathrm{S}$. The impedance data at each site were then decomposed using the fixed strike direction of $\mathrm{N} 5^{\circ} \mathrm{E}$ and frequencyindependent twist and shear. The decomposed data are shown as pseudo-sections in Fig. 3. After the decomposition, the galvanic distortion can still remain as static shift. This problem was solved along with the two-dimensional inversion.

\section{Two-Dimensional Resistivity Structure}

The decomposed data were then inverted using the twodimensional inversion codes of Ogawa and Uchida (1996). The initial model was a uniform earth of $100 \Omega \mathrm{m}$ resistivity. We divided the earth into $42 \times 57$ cells. In addition, the topography was incorporated into the model as the skin depth can be comparable to the topographic features (Ogawa et al., 1998). After the decomposition, the galvanic distortion still can remain as static shift and was therefore inverted as model parameters together with resistivity structures. In 
(a)

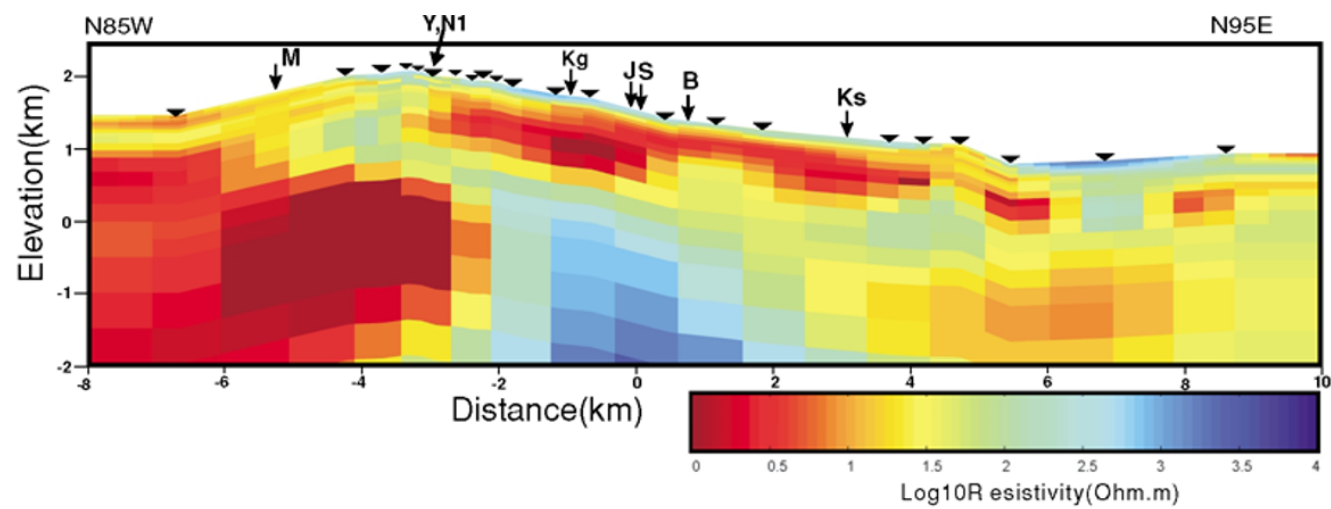

(b)

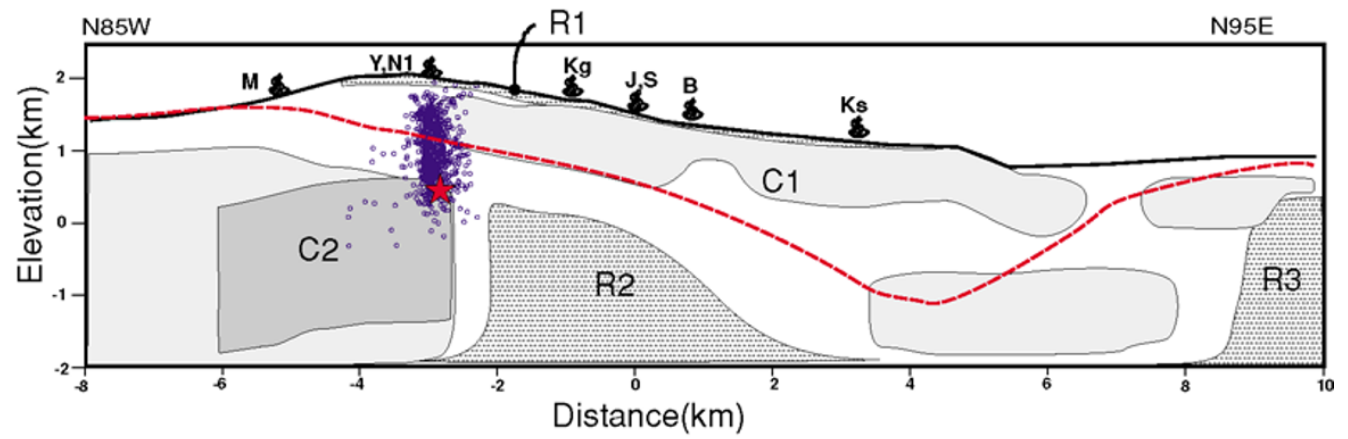

(C)

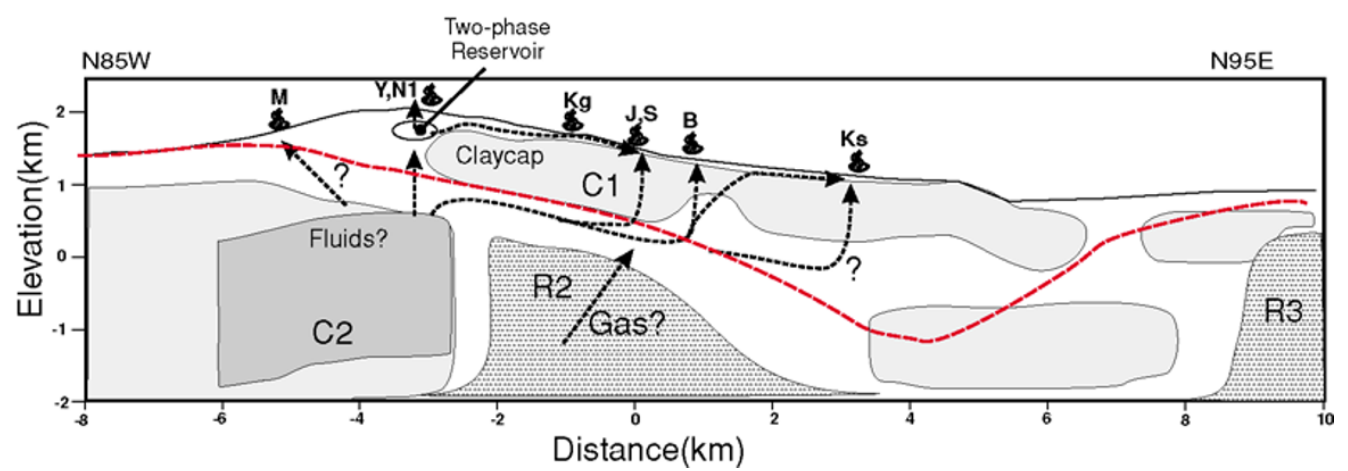

Fig. 4. (a) The final resistivity model. Triangles denote the locations of the audiomagnetotellurics sites. The labels with the arrows are: M, Manza hotspring; Y, Yugama crater; N1, N1 fumaroles; Kg, Kagusa hotspring; J, Jofu hotspring; S, Sessho fumaroles; B, Bandaiko hotspring; Ks, Kusatsu hot spring. (b) Simplified resistivity structure together with hypocenters of the volcanic micro-earthquakes (open circle), the center of deflation (red star), and the gravity basement (orange broken line). (c) Simplified geothermal system implied by the resistivity model. The two-phase reservoir inferred below the Yugama-Mizugama craters is inserted although it is not directly detected from the current AMT profiling.

the inversion, both apparent resistivity and phase for both modes were inverted with error floors of $10 \%$ for the apparent resistivities and the equivalent values for the phases. The final resistivity model (Fig. 4(a)) was obtained after 15 iterations. The rms of the model was 1.50 .

The resistivity model in Fig. 4(a) is simplified in Fig. 4(b). A conductive $(<5 \Omega \mathrm{m})$ zone, $\mathrm{C} 1$, that is covered with a thin resistive layer (R1) is located to the east part of Yugama crater. Below $\mathrm{C} 1$, are resistive layers R2 and R3 that show a syncline structure in the eastern part of the profile. A second conductive zone, C2, is located to the west of Yugama crater. These two conductors, however, are separated by a resistive gap beneath Yugama crater.

We tested the resistive gap between $\mathrm{C} 1$ and $\mathrm{C} 2$. If we connected the two conductors, the misfit became larger (1.89), indicating that the separation of these conductors is a significant factor. We also tested the bottom of the $\mathrm{C} 2$ conductor by changing its depth and found that the bottom of C2 should be deeper than $1 \mathrm{~km}$ below sea level.

\section{Discussion}

There is a significant difference in the resistivity structure beneath the two slopes (Fig. 4(a, b)). The eastern slope is characterized by the three-layered structure: the surface 200-m-thick layer of high resistivity (R1) that is underlain by a 300- to 1000-m-thick conductive layer (C1), and the resistive basement (R2 and R3). For the interpretation of the resistivity structure, we referred to information on the 1500m-deep borehole at 55GT-1 and 55GT-2 (Fig. 1) (Kurasawa, 1993). The borehole lithology and electrical logging information are summarized below using information provided by Kurasawa (1993) and Gunma Prefecture (1989). Within the borehole, the surface 200-m-thick resistive layer corresponds to the Quaternary lava of Kusatsu-Shirane volcano, 
which is underlain by a 1000-m-thick conductive layer of lava that is older than Kusatsu-Shirane volcano. The low resistivity of this layer is caused by the existence of Montmorillonite clay mineral. The electrical logging at 55GT-1 and 55GT-2 for the depth range containing the Montmorillonite clay mineral was $2-50 \Omega \mathrm{m}$, and this resistivity is compatible with that of the $\mathrm{C} 1$ conductor. This clay is a very important factor in the interpretation of the geothermal system for the following reasons. First, Montmorillonite is hydrologically impermeable as well as electrically conductive and, as such, this conductor constitutes the impermeable cap of the geothermal system. Second, the bottom of the conductive layer constitutes part of the geotherm of $200^{\circ} \mathrm{C}$ (e.g. Uchida, 1990; Harvey and Browne, 2000). The borehole electrical logging (Gunma prefecture, 1989) of 55GT-1 and $55 \mathrm{GT}-2$ revealed a more resistive $(>50 \Omega \mathrm{m}$ ) layer below the conductive layer. The difference in the electrical property is due to the presence of Montmorillonite. The temperature logging at the 55GT-1 borehole indicated a temperature of $200^{\circ} \mathrm{C}$ at the bottom of the conductive layer. The resistive layer below the Montmorillonite zone also contains clay minerals, but these are dominated by chlorite and quartz because Montmorillonite breaks down at temperature above $200^{\circ} \mathrm{C}$ (e.g. Uchida, 1990; Harvey and Browne, 2000). The 55GT-1 drill hole also encountered lost circulation and fractures containing acid fluids below the Montmorillonite-rich layer.

The three-layered structure in the eastern slope of Kusatsu-Shirane volcano can be interpreted using the above borehole information. The presence of the surface resistive layer (R1) implies the presence of Kusatsu-Shirane lava and a pyroclastic flow deposit (Taishi Pyroclastic flow deposit), while the presence of the horizontal conductive layer (C1) infers a Montmorillonite-rich zone that functions as an impermeable layer for the geothermal system in the eastern slope. The underlying resistive layers (R2 and R3) can be interpreted as being volcanic layers containing additional resistive clay minerals, such as chloride.

The impermeable layer $\mathrm{C} 1$ may function as an impermeable floor for the overlying geothermal fluids flowing from the summit as well as an impermeable cap for deeper fluids. According to the results of geochemical studies by Ohba et al. (2000) and Ohwada et al. (2003), fluids supplied to the eastern hot springs (Jofu and Kagusa) have the same origin as those supplied to Yugama. The fluids may flow through the shallow permeable zone (R1), and C1 may work as an impermeable floor.

The bottom of the $\mathrm{C} 1$ conductor has an undulation which shallows out at Bandaiko (B in Fig. 4(b, c)). This is supported by the AMT data. The thinned-out conductor was required by the relatively low TM phase at around $100 \mathrm{~Hz}$ at the two sites near Bandaiko (distance of around $1 \mathrm{~km}$ in Fig. 3), implying that the geotherm of $200^{\circ} \mathrm{C}$ is elevated around Bandaiko. This interpretation is also consistent with the geochemical study by Mizuhashi (2004), who revealed quantitatively the high volatile flux at Sessho and Bandaiko from below.

Our interpretation of the widespread existence of a conductor as a Montmorillonite-rich zone will elicit a great deal of discussion because Montmorillonite should break down in an acid environment like that found at Kusatsu-Shirane, where hot springs are known to have a low $\mathrm{pH}$ ranging from 1.21 to 4.21 (e.g. Kikawada et al., 1993). However, according to Kurasawa (1993), acid fluid was found in the 55GT-2 borehole in the tuff and mudstone layer (1244-1259 m) just below the Montmorillonite-containing layer, with the core samples of the Montmorillonite showing a $\mathrm{pH}$ of 9.1-9.5. Thus, the distribution of acid fluid does not contradict the existence of the Montmorillonite zone. In fact, Montmorillonite was also found in the ejecta from the 1976 eruption at Mizugama (Ossaka and Hirabayashi, 1981). We may therefore conclude that the Montmorillonite exists by selfsealing itself from the acid fluids. A similar Montmorillonite sealing of acid fluid has been observed and quantitatively realized at the Onikobe geothermal field in Japan (Todaka et al., 2003).

The resistivity structure of the eastern slope does not continue westward beyond the peak zone of Kusatsu-Shirane volcano. The $\mathrm{C} 2$ conductor is present at the peak and the western slope of the volcano, but it is located at a deeper level than $\mathrm{C} 1$. The resistivity of the $\mathrm{C} 2$ conductor is also almost one order of magnitude less than that of the Montmorillonite-rich layer of $\mathrm{C} 1$. Thus, we interpret the role of $\mathrm{C} 2$ as the block containing deep geothermal fluids, where magmatic gases condense. Ucok et al. (1980) measured the resistivity of fluids with a solution of $1000 \mathrm{ppm}$ $\mathrm{NaCl}$. The resistivity was $3 \Omega \mathrm{m}$ at around $400^{\circ} \mathrm{C}$. As the concentration of the chloride in the original fluid in which magmatic gases fully condense is estimated to be as high as 22,000 ppm for Kusatsu-Shirane volcano (Hirabayashi, 1999), the corresponding fluid conductivity may have the order of $0.1 \Omega \mathrm{m}$ or less. Moreover, the contribution of sulfate from the magmatic gases into the fluid $(33,000 \mathrm{ppm})$ (Hirabayashi, 1999) will further lower the resistivity by $50 \%$. Both of these facts can explain the low resistivity of the $\mathrm{C} 2$ conductor.

Figure 4(b) also includes micro-earthquake hypocenters determined by the Seismic Network of Tokyo Institute of Technology (Mori et al., 2006). The hypocenters are located above the $\mathrm{C} 2$ conductor. The cut-off depth of the hypocenters almost coincides perfectly with the top of the conductor, indicating that the fluids may exist just under the brittle-ductile boundary of $350-400^{\circ} \mathrm{C}$. Similar configurations of geotherm, seismicity, and resistivity have been reported by Ogawa et al. (2001, 2002), Ogawa and Honkura (2004), and Kasaya et al. (2002) for intraplate earthquake zones. Murakami et al. (2004) analyzed the GPS and leveling data from 1992 to 2003 and located the causative spherical zone $\left(0.7 \times 10^{6} \mathrm{~m}^{3}\right)$ for the deflation at the top of the C2 conductor (See the star in Fig. 4(b)). Thus, the deep geothermal fluid reservoir presumably provides an easily deformable zone.

The resistivity structure was compared with the density model. The regional gravity data (Hiroshima et al., 1994; Geological Survey of Japan, 2004) along the AMT profile between the two end sites was interpreted by a two-layered density model. Prior to the modeling, the basement density of $2.56 \mathrm{~g} / \mathrm{cm}^{3}$ was inferred from the F-H relationship of the regional data of 269 points (Makino et al., 2004) without removing the regional trend. This basement probably 
corresponds to the underlying Miocene rocks. Likewise, the density of the surface volcanic rocks was assumed to be $2.29 \mathrm{~g} / \mathrm{cm}^{3}$ from the F-H relationship after the regional trend had been removed. The estimated basement depth was projected onto the AMT model as shown in Fig. 4(b, c). The gravity basement is almost exposed at both ends of the profile and is the deepest east of the Kusatsu hot spring, where gravity is at its minimum. Interestingly, the $\mathrm{C} 1$ conductor is just above the gravity basement. The borehole data at 55GT-1 found Miocene volcanic rocks under the Montmorillonite-rich layer. The C2 conductor, however, is located within the gravity basement. This result may also support our interpretation that the $\mathrm{C} 1$ and $\mathrm{C} 2$ conductors are of different origins.

Figure 4(c) summarizes the resistivity structure and the schematic geothermal system. The fluid reservoir (C2) of magmatic gas condensation seems to exist under the summit region at a depth below $1.5 \mathrm{~km}$. Fluids or gases from the reservoir are supplied upward underneath the summit region, and these presumably trigger tectono-volcanic microearthquakes. Based on geochemical studies (Ohba et al., 2000) and seismic tremor studies (Kumagai et al., 2002; Nakano et al., 2003), the two-phase reservoir is inferred at a depth $300 \mathrm{~m}$ below the Yugama-Mizugama region, but our resistivity model does not show any corresponding structures because the AMT profile is off the two-phase reservoir. Subsequent detailed mapping around the YugamaMizugama craters (Nurhasan et al., in preparation) found that there is an additional capping structure for the twophase reservoir surrounding the Yugama and Mizugama but that the current profile does not cross such anomalies.

The gases from the two-phase reservoir are supplied to the Yugama crater lake and the surrounding fumaroles, such as N1, whereas the fluids from the two-phase reservoir would flow down to the Kagusa $(\mathrm{Kg})$ and Jofu (J) hot springs. This model is consistent with the geochemical evidence that these fluids have the same origin as those of Yugama crater lakes. This flow may use the clay layer (C1) as an impermeable floor.

Another fluid path would be at deeper level in which C1 is used as a capping layer; this path explains the large mass output (Mizuhashi, 2004) at Bandaiko. In the vicinity of Bandaiko, the shallow bottom of the $\mathrm{C} 1$ conductor probably implies the presence of the currently elevated $200^{\circ} \mathrm{C}$ geotherm. This geotherm requires extra heating underneath the Bandaiko, and its presence will also explain the fumarole of Sessho; however, we have no relevant deep resistivity structure.

On the western side of the volcano, we have Manza hot springs and fumaroles ( $\mathrm{M}$ in Fig. 4). The resistivity structure is significantly different from that of the eastern slope. However, the fluid path to the Manza is not easily explained under the constraints of the present investigation.

\section{Conclusion}

Audio-magnetotelluric soundings along a profile that extends across Kusatsu-Shirane volcano revealed the presence of two conductors.

The first conductor is a 300 - to 1000 -m-thick layer located on the eastern slope of the volcano that is covered with a 200-m-thick layer of Kusatsu-Shirane lava and pyroclastics. The implications of the conductor were studied using well logging information from the boreholes (Kurasawa, 1993). The presence of this conductor implies that the Montmorillonite-rich layer of the Pliocene-Pleistocene volcanic rocks is electrically conductive but hydrologically impermeable. The impermeability of the layer implies two possible two fluid paths. The first fluid path uses the impermeable layer as a floor in the area extending from the Yugama-Mizugama fluid reservoir to the eastern hot springs of Kagusa and Jofu and is experimentally supported by the results of geochemical studies indicating that all of the constituents are of the same origin (Ohba et al., 2000; Ohwada et al., 2003). A second fluid path would be deeper and extend under the conductor, where the impermeable layer would function as a cap of the geothermal system. The large amount of volatile flux at Bandaiko requires a fluid supply from underneath the impermeable layer, while the shallow bottom of the conductor at the Bandaiko hot spring implies an elevated isotherm of $200^{\circ} \mathrm{C}$.

The second conductor was found at a depth of 1-2 km from the surface, at the peak of the volcano. This conductor is located deeper than the first one. The sensitivity test revealed that the separation of these two conductors is significant. Above the conductor, micro-earthquakes cluster and the cut-off of the earthquakes corresponds to the top of the conductor. The presence of this conductor implies that the fluid reservoir is trapped under the brittle ductile boundary and that the upward release of the fluid presumably triggers the micro-earthquakes. The low resistivity $(\sim 1 \Omega \mathrm{m})$ can be explained by the high concentration of chloride and sulfate as a result of the condensation of the magmatic gases into the fluid reservoir. The deflation of the volcano during the past 10 years is also located at the top of the conductor $(\mathrm{Mu}-$ rakami et al., 2004). This fluid reservoir may be responsible for the deformable zone of the volcano.

On the basis of the sensitivity test of the resistivity model, the two conductors are significantly separated. The gravity study also supports the different nature of the two conductors; $\mathrm{C} 1$ is located above the Miocene volcanic basement, whereas the $\mathrm{C} 2$ is located in the basement.

Acknowledgments. The authors are grateful to Junichi Hirabayashi, Takeshi Ohba, Kenji Nogami, and Shinichi Takakura for their fruitful discussion. The critical reviews by Wataru Kanda and Takao Koyama greatly improved the manuscript.

\section{References}

Aizawa, K., R. Yoshimura, N. Oshiman, K. Yamazaki, T. Uto, Y. Ogawa, S. B. Tank, W. Kanda, S. Sakanaka, Y. Furukawa, T. Hashimoto, M. Uyeshima, T. Ogawa, I. Shiozaki, and A. Hurst, Hydrothermal System beneath Mt. Fuji volcano inferred from magnetotellurics and electric self-potential, Earth Planet. Sci. Lett., 235, 343-355, 2005.

Çağlar, İ. and T. İşseven, Two-dimensional geoelectrical structure of the Göynük geothermal area, northwest Anatolia, Turkey, J. Volcanol. Geotherm. Res., 134, 183-197, 2004.

Di Maio, R., P. Mauriello, D. Patella, Z. Petrillo, S. Piscitelli, and A. Siniscalchi, Electric and electromagnetic outline of the Mount SommaVesuvius structural setting, J. Volcanol. Geotherm. Res., 82, 219-238, 1998.

Fuji-ta, K., Y. Ogawa, M. Ichiki, S. Yamaguchi, and Y. Makino, Audio frequency magneto-telluric survey of Norikura Volcano in central Japan, J. Volcanol. Geotherm. Res., 90, 209-217, 1999.

Geological Survey of Japan, Geological map of Japan, 1:200,000, Nagano, 
1998.

Geological Survey of Japan (ed.), Gravity CD-ROM of Japan, Ver. 2, Digital Geoscience Map P-2, Geological Survey of Japan, 2004.

Groom, R. W. and R. C. Bailey, Decomposition of magnetotelluric impedance tensor in the presence of local three-dimensional galvanic distortion, J. Geophys. Res., 94, 1913-1925, 1989.

Gunma Prefecture, Report on the geothermal survey around KusatsuShirane volcano, 374 pp, 1989 (in Japanese).

Harvey, C. and P. Browne, Mixed-layer clays in geothermal systems and their effectiveness as mineral geothermometers, Proceedings World Geothermal Congress 2000, Kyushu-Tohoku, Japan, May 28-June 10, 1201-1204, 2000.

Hirabayashi, J., Formation of volcanic fluid reservoir and volcanic activity, J. Balneol. Soc. Jpn., 49, 99-105, 1999 (in Japanese with English abstract).

Hirabayashi, J., T. Ohba, and K. Nogami, Hydrothermal system of Kusatsu-Shirane volcano and Kirishima volcanic area inferred from geochemical observations, 53-62, in Magma prospecting present and future perspective, Proc. Disas. Prev. Res. Inst. Symp. (8K-6), Kyoto University, 1997 (in Japanese with English abstract).

Hiroshima, T., M. Komazawa, and T. Nakatsuka, Gravity map of JoshinEtsu District (Bouguer anomalies), Gravity Map Series, no. 5, Geological Survey of Japan, 1994.

Kagiyama, T., H. Utada, and T. Yamamoto, Magma ascent beneath Unzen Volcano, SW Japan, deduced from the electrical resistivity structure, $J$. Volcanol. Geotherm. Res., 89, 35-42, 1999.

Kasaya, T., N. Oshiman, N. Sumitomo, M. Uyeshima, Y. Iio, and D. Uehara, Resistivity structure around the hypocentral area of the 1984 Western Nagano Prefecture earthquake in central Japan, Earth Planets Space, 54, 107-118, 2002.

Kikawada, Y., T. Oi, T. Honda, T. Ossaka, and H. Kakihara, Lanthanoid abundances of acidic hot spring and crater lake waters in the KusatsuShirane volcano region, Japan, Geochem. J., 27, 19-33, 1993.

Kumagai, H., B. A. Chouet, and M. Nakano, Temporal evolution of a hydrothermal system in Kusatsu-Shirane Volcano, Japan, inferred from the complex frequencies of long-period events, J. Geophys. Res., 107(B10), 2236, doi:10.1029/2001JB000653, 2002.

Kurasawa, T., Problem with the drilling of geothermal well in the south of Mt. Kusatsu-Shirane, Gunma Prf., J. Japan Geothermal Energy Assoc., 30, 1-23, 1993 (in Japanese with English abstract).

Makino, M., S. Watanabe, T. Sumita, and Y. Ogawa, Microgravity Survey in the vicinity of the Kusatsu-Shirane Summit, report on the 4th joint observation of Kusatsu-Shirane volcano, 69-80, 2004 (in Japanese).

Manzella, A., G. Volpi, A. Zaja, and M. Meju, Combined TEM-MT investigation of shallow-depth resistivity structure of Mt Somma-Vesuvius, J. Volcanol. Geotherm. Res., 131, 19-32, 2004.

Matsushima, N., H. Oshima, Y. Ogawa, S. Takakura, H. Satoh, M. Utsugi, and Y. Nishida, Magma prospecting in Usu volcano, Hokkaido, Japan, using magnetotelluric soundings, J. Volcanol. Geotherm. Res., 109(4), 263-277, 2001

Mizuhashi, S., Geothermal system of Kusatsu-Shirane volcano inferred from the volatile mass flux, Master thesis, Tokyo Institute of Technology, 69 pp., 2004 (in Japanese).

Mori, T., J. Hirabayashi, K. Nogami, and S. Onizawa, A new seismic observation system at the Kusatsu-Shirane volcano, Bull. Volcanol. Soc. Japan, Ser. 2, 51, 41-47, 2006 (in Japanese with English abstract).

Müller, A. and V. Haak, 3-D modeling of the deep electrical conductivity of Merapi volcano (Central Java): integrating magnetotellurics, induction vectors and the effects of steep topography, J. Volcanol. Geotherm. Res., 138(3-4), 205-222, 2004

Murakami, M., A. Kagawa, A. Yamada, H. Satoh, M. Yokokawa, T. Kimura, T. Kawamoto, K. Mori, and A. Suzuki, A deflation source beneath Kusatsu-Shirane volcano inferred from repeated campaign measurements of GPS and precise leveling, 4th Joint Observation of Kusatsu-Shirane Volcano, 31-36, 2004 (in Japanese).

Nakano, M., H. Kumagai, and B. A. Chouet, Source mechanism of long-period events at Kusatsu-Shirane Volcano, Japan, inferred from waveform inversion of the effective excitation functions, J. Volcanol. Geotherm. Res., 122, 149-164, 2003.

Ogawa, Y., On two-dimensional modeling of magnetotelluric field data, Surv. Geophys., 23(2-3), 251-273, 2002.

Ogawa, Y. and Y. Honkura, Mid-crustal electrical conductors and their correlations to seismicity and deformation at Itoigawa-Shizuoka Tectonic Line, Central Japan, Earth Planets Space, 56, 1285-1291, 2004.

Ogawa, Y. and S. Takakura, CSAMT measurement across the 1986 C
Craters of Izu-Oshima Island, Japan, J. Geomag. Geoelectr., 42, 211224, 1990.

Ogawa, Y. and T. Uchida, A two-dimensional magnetotelluric inversion assuming Gaussian static shift, Geophys. J. Int., 126, 69-76, 1996.

Ogawa, Y., S. Takakura, and T. Soya, Wideband magnetotelluric measurements across Izu-Oshima volcano, J. Geomag. Geoelectr., 44, 561-566, 1992.

Ogawa, Y., N. Matsushima, H. Oshima, S. Takakura, M. Utsugi, K. Hirano, M. Igarashi, and T. Doi, A resistivity cross-section of Usu volcano, Hokkaido, Japan, by audiomagnetotellurics soundings, Earth Planets Space, 50, 339-346, 1998.

Ogawa, Y., H. M. Bibby, T. G. Caldwell, S. Takakura, T. Uchida, N. Matsushima, S. L. Bennie, T. Tosha, and Y. Nishi, Wide-band magnetotelluric measurements across the Taupo Volcanic Zone, New Zealandpreliminary results, Geophys. Res. Lett., 26, 3673-3676, 1999.

Ogawa, Y., M. Mishina, T. Goto, H. Satoh, N. Oshiman, T. Kasaya, Y. Takahashi, T. Nisitani, S. Sakanaka, M. Uyeshima, Y. Takahashi, Y. Honkura, and M. Matsushima, Magnetotelluric imaging of fluid in the interpolate earthquake zone, NE Japan back arc, Geophys. Res. Lett., 28, 3741-3744, 2001.

Ogawa, Y., S. Takakura, and Y. Honkura, Resistivity structure across Itoigawa-Shizuoka tectonic line and its implications for concentrated deformation, Earth Planets Space, 54, 1115-1120, 2002.

Ohba, T., Geothermal system of Kusatsu-Shirane volcano, in Volcanic Structure in the Shallow Part and Volcanic Fluid, Proc. Disas. Prev. Res. Inst. Symp.(12K-3), Kyoto Univ., 161-168, 2002 (in Japanese).

Ohba, T., J. Hirabayashi, and K. Nogami, Water, heat and chloride budgets of the crater lake, Yugama, at Kusatsu-Shirane volcano, Geochem. J., 28, 217-231, 1994.

Ohba, T., J. Hirabayashi, and K. Nogami, D/H and ${ }^{18} \mathrm{O} /{ }^{16} \mathrm{O}$ ratios of water in the crater lake at Kusatsu-Shirane volcano, Japan, J. Volcanol. Geotherm. Res., 97, 329-346, 2000.

Ohwada, M., T. Ohba, J. Hirabayashi, K. Nogami, K. Nakamura, and K. Nagao, Interaction between magmatic fluid and meteoric water, inferred from ${ }^{18} \mathrm{O} /{ }^{16} \mathrm{O}$ and ${ }^{36} \mathrm{Ar} / \mathrm{H}_{2} \mathrm{O}$ ratios of fumarolic gases at the KusatsuShirane volcano, Japan, Earth Planets Space, 55, 105-110, 2003.

Oskooi, B., L. B. Pedersen, M. Smirnov, K. Árnason, H. Eysteinsson, A Manzella, and the DGP Working Group, The deep geothermal structure of the Mid-Atlantic Ridge deduced from MT data in SW Iceland, Phys. Earth Planet. Inter., 150, 183-195, 2005.

Ossaka, J. and J. Hirabayashi, Clay minerals in volcanic ejecta, J. Mine Soc. Jpn., 15, 223-228, 1981 (in Japanese with English abstract).

Pellerin, L., J. M. Johnston, and G. W. Hohmann, A numerical evaluation of electromagnetic methods in geothermal exploration, Geophysics, 61 , 121-130, 1996.

Sano, Y., J. Hirabayashi, T. Oba, and T. Gamo, Carbon and helium isotopic ratios at Kusatsu-Shirane Volcano, Japan, Appl. Geochem., 9, 371-377, 1994.

Takeda, T., H. Sato, T. Iwasaki, N. Matsuta, S. Sakai, T. Iidaka, and A. Kato, Crustal structure in the northern Fossa Magna region, central Japan, modeled from refraction/wide-angle reflection data, Earth Planets Space, 56, 1293-1299, 2004.

Todaka, N., C. Akasaka, T. Xu, and K. Pruess, Reactive Geothermal Transport Simulation to Study the Formation Mechanism of Impermeable Barrier between Acidic and Neutral Fluid Zones in the Onikobe Geothermal Field, Japan, LBNL-52493, Lawrence Berkeley National Laboratory, University of California, Berkeley, 37 pp, 2003.

Uchida, T., Reservoir structure of the Sengan geothermal field interpreted from the resistivity data, J. Geotherm. Res. Soc. Japan, 12, 1-21, 1990 (in Japanese with English abstract).

Ucok, H., I. Ershaghi, and G. Olhoeft, Electrical resistivity of geothermal brines, J. Petrol. Technol., 32(4), 717-727, 1980.

Uto, K., Y. Hayakawa, S. Aramaki, and J. Ossaka, Geological map of Kusatsu-Shirane volcano, Geological Survey of Japan, 1983 (in Japanese)

Yamazaki, A., M. Churei, S. Tsunomura, and S. Nakajima, Analysis of the variation of geomagnetic total force at Kusatsu-Shirane volcano: the remarkable changes in the geomagnetic total force in 1990 and the estimated thermal demagnetization model, Mem. Kakioka Mag. Obs., 24(2), 53-66, 1992 (in Japanese with English abstract).

Nurhasan, Y. Ogawa (e-mail: oga@ksvo.titech.ac.jp), N. Ujihara, S. B. Tank, Y. Honkura, S. Onizawa, T. Mori, and M. Makino 